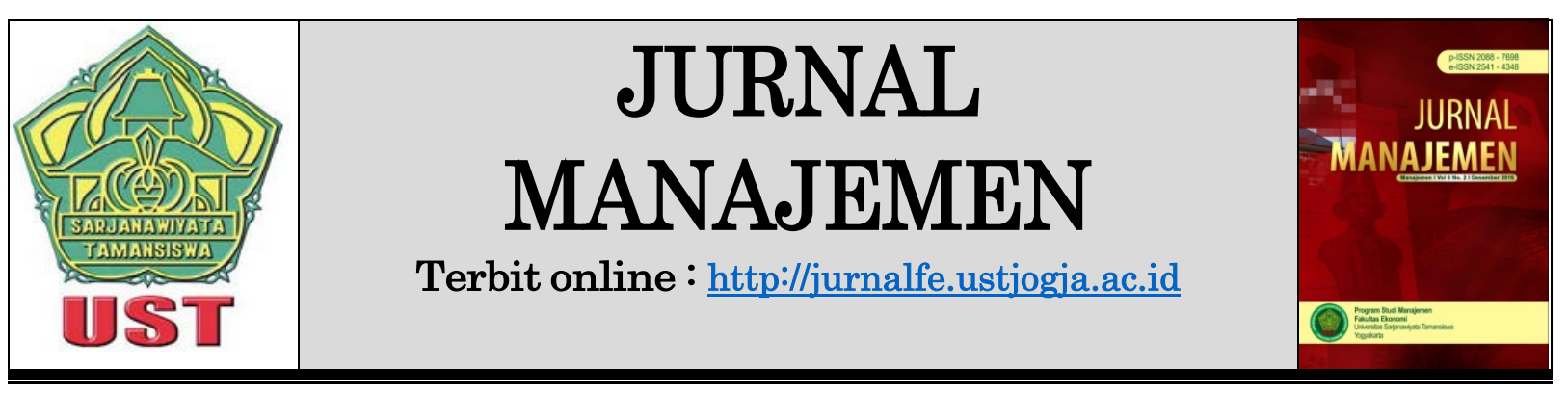

\title{
BANK PERKREDITAN RAKYAT, KEPERCAYAAN DAN LOYALITAS NASABAH
}

\author{
Ahsan Sumantika ${ }^{1}$ \\ Adhi Prakosa ${ }^{2}$ \\ ${ }^{12}$ Universitas PGRI Yogyakarta \\ Email korespondensi: adhi@upy.ac.id
}

\begin{tabular}{ll}
\hline Informasi Naskah & Abstrak \\
\hline Diterima: & Rural bank (BPR) is one of type of bank known to serve \\
01 April & the micro, small and medium, especially in lending. As with \\
Revisi: & commercial banks, BPR have the same function as \\
- & intermediate institutions that connect parties with excess \\
Terbit: 8 Juni & funds with those in need of funds. At this time as the \\
Kata Kunci: Rural & economic policy changes, the challenges faced by BPR banks \\
Bank, Trust, Loyalty & are getting higher. BPR must maintain the trust of \\
& customers to maintain customer loyalty while at the same \\
& time the commercial banks participate in distributing credit \\
& in the sector of SMEs. \\
& This study aims to examine whether customer confidence \\
& in BPR banks have an effect on customer loyalty. Sampling \\
& technique used is purposive sampling that is customer which \\
& have loan at PD BPR Bantul. The data used are primary \\
& data obtained through questionnaire. The sampling period \\
& was conducted in April-May 2018 with a total sample of 45 \\
& debitors PD BPR Bantul. \\
& The test results show that based on t test, showed that \\
& trust has a positive and significant impact on customer \\
loyalty with asig value 0.000. The value of $R$ Square is 0.332 \\
indicates that there are still many other factors outside the \\
trust aproximately 66.8\% which explain customer loyalty.
\end{tabular}

\section{PENDAHULUAN}

Bank perkreditan rakyat adalah salah satu jenis bank yang dikenal melayani golongan mikro, kecil dan menengah. Menurut Undang-Undang No. 10 tahun 1998 terdapat dua jenis bank yakni 1) bank umum dan 2) bank perkreditan rakyat (BPR). Kedua jenis bank tersebut mempunyai tugas yang sama yakni sebagai lembaga intermediate yang menjembatani pihak yang mempunyai kelebihan dana dengan pihak yang membutuhkan dana. Dengan 
kata lain baik bank umum dan bank perkereditan rakyat mempunyai tugas dalam hal penghimpunan dana masyarakat dan menyalurkan kembali dalam bentuk kredit. Perbedaanya bank perkereditan rakyat dengan bank umum yakni bank BPR hanya berfokus pada sektor usaha mikro kecil menengah (UMKM) pada pinjaman usaha dan tidak diperkenankan untuk melakukan usaha lain seperti transaksi valas, pembukaan giro, asuransi dan lain sebagainya sesuai ketentuan yang di atur. Dengan fokus pada golongan mikro kecil, BPR diharapkan dapat menggerakkan sektor mikro kecil.

Pada saat ini, persaingan dalam industri perbankan semakin tinggi. Banyak bank baru bermunculan, dan memberikan penawaran-penawaran untuk menarik calon konsumen. Adanya peraturan baru dari Bank Indonesia menambah persaingan di sektor UMKM. Menurut peraturan Bank Indonesia No. 14/22/PBI/2012 menyatakan bahwa setiap Bank Umum wajib untuk menyalurkan Kredit atau pembiayaan UMKM paling rendah 20\% dari total kredit atau pembiayaan yang disalurkan pada tahun 2018 .

Terdapat banyak faktor yang mempengaruhi loyalitas nasabah. Salah satunya adalah kepercayaan. Wijayana (2016) mengatakan bahwa kepercayaan berpengaruh kepada loyalitas. Kepercayaan merek akan menentukan loyalitas atau kesetiaan konsumen terhadap merek dan kepercayaan. Bagi perbankan, loyalitas suatu nasabah merupakan kunci agar perusahaan itu tetap bisa bertahan dari para pesaing- pesaingnya. Jika tingkat kepercayaan konsumen tinggi, maka akan berpengaruh terhadap loyalitas konsumen. Konsumen yang loyal adalah aset yang berharga bagi perusahaan.

Sirdeshmukh, et al (2002) engatakan bahwa faktor penting dalam hubungan antara konsumen dan penyedia jasa adalah kepercayaan. Untuk menjaga pelanggan tetap loyal, bank sebagai penyedia jasa keuangan harus menjaga kepercayaan nasabah. Dengan kemajuan teknologi seperti internet yang sudah digunakan di sektor perbankan, transaksi keuangan menjadi semakin cepat dan mudah. Di satu sisi, ada resiko besar dengan kejahatan cyber yang mengancam nasabah. Untuk itu memberikan pelayanan terbaik agar tercipta kepercayaan.

Dalam konteks pemasaran, pelanggan yang setia akan bermanfaat bagi perusahaan. Semakin tinggi loyalitas seorang nasabah menyebabkan dirinya enggan untuk beralih ke bank lain. Nasabah akan cenderung akan selalu menyetujui dan mengikuti program-program atau layanan yang diberikan oleh pihak bank dan mereka selalu melakukan pembelian ulang. Semakin tinggi loyalitas seorang nasabah menyebabkan dirinya enggan untuk beralih ke bank lain yang memberikan program serupa.

Di benak konsumen, BPR sebenarnya sudah memiliki posisi yang cukup baik di sektor mikro kecil. Perbedaan dengan bank umum bisa dalam hal gedung fisik yang berbeda tentunya menimbulkan persepsi dan kepercayaaan yang berbeda. Akan tetapi kepercayaan tidak semata mata melihat dari gedung yang megah. Kepercayaan menunjukkan bahwa nasabah percaya bahwa bank keberadaan BPR memiliki niat dan motif bermanfaat bagi pelanggan dan menciptakan hasil yang positif kepada nasabah. Sedangka menurut Ndubisi (2007) indikator dari kepercayaan antara lain a) bank sangat peduli dengan keamanan ketika transaksi konsumen, b) bank 
menjanjikan produk dan layanan yang dapat diandalkan c) bank konsisten dalam memberikan layanan yang berkualitas d) karyawan bank menunjukkan rasa hormat kepada pelanggan 2) eank memenuhi kewajibannya terhadap konsumen

Menjaga kepercayaan nasabah bukanlah hal yang mudah. BPR menghadapi persaingan dengan bank umum yang memiliki teknologi lebih unggul. Di era internet banking seperti sekarang, BPR masih dipercaya oleh masyarakat hanya sebagai tempat untuk melakukan peminjaman uang atau kredit. Untuk menawarkan produk-produk keuangan lainnya selain kredit, BPR harus berusaha meraih kepercayaan masyarakat. Tentunya persaingan dengan bank umum adalah hal yang tidak bisa dihindari. Beberapa bank umum memiliki segmen yang sama dengan segmen yang dilayani oleh BPR. Nasabah bank cenderung sulit berpindah bank karena mereka memiliki kewajiban terhadap bank, tidak ada alternatif lain untuk mereka pilih, atau karena sudah memiliki kepercayaan terhadap bank pilihannya lebih dari bank lainnya (Gudlaugsson \& Eysteinsson, 2013). Untuk itu, jika nasabah memiliki kewajiban terhadap bank bukanlah hal yang sulit untuk menjaga kesetiaan, akan tetapi merupakan keharusan untuk memberikan pelayanan agar tercipta citra positif dari pengalaman.

PD BPR Bank Bantul adalah salah satu bank BPR yang beroperasi melayani penyaluran kredit di sektor UMKM. PD BPR Bantul adalah bank yang dimiliki oleh Pemerintah Kabupaten Bantul beralamat di Jalan Gajah Mada No. 3 Bantul. PD BPR, bank bantul memiliki reputasi yang lebih dibanding bank BPR lain. Menurut Nurdiansyah salah satu menjadi kekutan internal (streght) dari bank bantul adalah karena bank tersebut memiliki nama baik dan sudah dikenal lama sejak tahun 1983 serta memiliki kepercayaan dan reputasi yang baik dari segi SDM dan kualitas pelayanan. Berdasarkan latar belakang tersbut, maka peneliti berniat melakukan penelitian pengaruh kepercayaan (trust) terhadap loyalitas nasabah (debitur) bank BPR terutama PD BPR Bank Bantul.

\section{KAJIAN PUSTAKA DAN HIPOTESIS}

Loyalitas berarti kesetiaan seorang pelanggan terhadap merek atau layanan tertentu. Dalam konteks pemasaran, pelanggan yang setia akan bermanfaat bagi perusahaan. Semakin tinggi loyalitas seorang nasabah menyebabkan dirinya enggan untuk beralih ke bank lain. Nasabah akan cenderung akan selalu menyetujui dan mengikuti program-program atau layanan yang diberikan oleh pihak bank dan mereka selalu melakukan pembelian ulang.

Dampak dari loyalitas adalah pemasukan yang besar bagi perusahaan. Di perbankan, nasabah yang loyal sangat penting bagi sebuah bank. Mereka adalah pengguna produk-produk perbankan yang ditawarkan oleh bank tertentu. Ini memberikan keuntungan ekonomi bagi bank. Pengaruh lainnya adalah nasabah yang loyal dapat memberikan referensi positif melalui word of mouth atau melalui media sosial. Di era internet seperti sekarang ini, ulasan yang ditulis melalui media sosial akan menjadi ajang publikasi positif bagi bank di mata masyarakat. Menurut Griffin (2006), loyalitas diukur dengan menggunakan lima komponen yaitu pembelian ulang, rekomendasi, 
menambah jumlah produk, menceritakan hal-hal yang positif, kesediaan menerima harga yang berubah-ubah.

Banyak faktor yang mempengaruhi loyalitas pelanggan terhadap bank, jika dinilai dari aspek sumber daya manusia dan aspek fisik diantaranya adalah perhatian yang diberikan oleh karyawan, pemahaman karyawan terhadap kebutuhan pelanggan, pengetahuan untuk menjawab pertanyaan pelanggan, kesopanan karyawan, penampilan karyawan yang modern, fasilitas fisik peralatan penunjang di bank, tidak adanya kesalahan pencatatan, dan keamanan dalam transaksi keuangan (Hazra \& Srivastava, 2009).

Memberikan pelayanan yang baik bagi nasabah akan menimbulkan pengalaman positif. Pengalaman ini menjadi nilai yang akan berpengaruh terhadap kesetiaan konsumen. BPR sebagai perusahaan jasa harusnya dapat menjaga kepercayaan dengan melibatkan mereka melalui layanan dan produk keuangan yang ditawarkan. Konsumen yang lebih banyak terlibat akan mempengaruhi loyalitas dan mereka dapat digunakan sebagai pertahanan dalam menghadapi ancaman dari pesaing (Wyman, 2015). Untuk mendapatkan kepercayaan dan loyalitas pelanggan maka keunggulan nilai dan pelayanan adalah salah satu faktor yang harus dipertimbangkan. Pelayanan dapat berpengaruh positif bagi kepuasan dan kepercayaan pelanggan untuk meningkatkan loyalitas mereka (Rusli, 2011).

\section{Pembentukan Hipotesis}

Kepercayaan adalah modal utama untuk membangun loyalitas pelanggan. Kepercayaan adalah kesediaan untuk mengandalkan pada mitra pertukaran yang satu memiliki keyakinan. (Moorman et al., 1993). Sedangkan loyalitas adalah kesetiaan seorang nasabah terhadap suatu lembaga atau bank. Untuk memperbaiki pelayanan terhadap konsumen, maka bank sebaiknya selalu melakukan perbaikan secara terus-menerus. Jika konsumen puas dengan pelayanan yang diberikan oleh bank, maka kontribusi keterlibatan dan kepercayaan terhadap bank akan tinggi, sehingga kepuasan konsumen berpengaruh terhadap loyalitas mereka (Arfai, Valashejerdi, \& Najafi, 2013).

Terdapat beberapa penelitian yang menguji pengaruh kepercataan terhadap loyalitas nasabah di bank BPR. Penelitian yang dilakukan oleh Setiawan et al (2007) menunjukkan bahwa kepercayaan dapat mempengaruhi loyalitas nasabah BPR (Setiawan \& Ukudi, 2007). Penelitian lain juga dilakukan oleh Wijayana (2016) menunjukkan bahwa kepercayaan berpengaruh kepada loyalitas. Bagi perbankan, loyalitas nasabah merupakan kunci agar perusahaan tetap bisa bertahan dari para pesaingnya. Jika tingkat kepercayaan konsumen tinggi, maka akan berpengaruh terhadap loyalitas konsumen. Konsumen yang loyal adalah aset yang berharga bagi perusahaan. Berdasarkan hal tersebut maka dihipotesiskan :

Hipotesis 1

Tingkat Kepercayaan Nasabah Berpengaruh Positif Terhadap Loyalitas 


\section{METODE PENELITIAN \\ Teknik Sampling dan Data}

Teknik sampling yang digunakan yakni purposive sampling yakni teknik pengumpulan data yang didasarkan pada kriteria-kriteria tertentu. Kriteria sampel yang digunakan adalah para nsasabah bank yang mempunyai pinjaman usaha (debitur) di PD BPR Bantul. Data yang digunakan adalah data primer yang didapatkan secara langsung melalui kuesioner. Jumlah sampel yang digunakan yakni 45 debitur PD BPR Bantul.

\section{Variabel dan Definisi Operasional}

1. Kepercayaan (Trust)

Kepercayaan adalah kesediaan untuk mengandalkan pada mitra pertukaran yang satu memiliki keyakinan. (Moorman et al., 1993). Indikator dari kepercayaan antara lain

a. Nasabah percaya bahwa bank keberadaan BPR memiliki niat dan motif bermanfaat bagi pelanggan

b. Menciptakan hasil yang positif kepada nasabah Sedangka menurut Ndubisi (2007) indikator dari kepercayaan antara lain :

a. Bank sangat peduli dengan keamanan ketika transaksi konsumen,

b. Bank menjanjikan produk dan layanan yang dapat diandalkan

c. Bank konsisten dalam memberikan layanan yang berkualitas

d. Karyawan bank menunjukkan rasa hormat kepada pelanggan

e. Bank memenuhi kewajibannya terhadap konsumen

2. Loyalitas (Loyality)

Loyalitas adalah kesetiaan seorang nasabah terhadap suatu lembaga atau bank. Menurut Griffin (dalam www.untukku. com.2006 : 223), variabel ini diukur dengan menggunakan lima komponen yaitu :
a. Pembelian ulang
b. Rekomendasi
c. Menambah jumlah produk
d. Menceritakan hal-hal yang positif
e. Kesediaan menerima harga yang berubahubah sesuai tipe

\section{Teknik Analisis Data}

1. Uji Instrumen

Sebelum dilakukan uji hipoteis peneliti membangun sebuah instrumen penelitian dengan melakukan uji validitas dan reabilitas. Jumlah sampel yang digunakan sebanyak 30 rerspnden. Uji validitas digunakan untuk menguji apakah instrumen yang dibangun dapat mengukur apa yang seharusnya diukur. Alat uji yang digunakan dalam uji validitas adalah analisis korelasi skor item pertanyaan dengan skor total. Kriteria dinyatakan valid jika nilai korelasi item pertanyaan dengan skor total lebih dari 0.3. Sedangkan uji reabilitas digunakan untuk mengukur sejauh mana hasil pengukuran tetap konsisten. Sedangkan alat uji reabilitas adalah cronbach alpha.. Kriteria dinyatakan reliabel jika nilai cronbach alpha lebih dari 0.6

Item-item pertanyaan dalam kuesioner disusun dalam skala likert 
yang terdiri dari 5 skala penilaian. Skala 1 menunjukkan sangat tidak setuju, skala 2 tidak setuju, skala 3 netral, skala 4 sangat setuju dan skala 5 menunjukkan sangat setuju.

2. Pengujian Hipotesis

Setelah semua item pertanyaan memenuhi uji validitas dan reliabilitas, peneliti melakukan pengujian hipotesis menggunakan analisis regresi sederhana. Analis regresi yang digunakan jika hanya terdapat satu variabel independen.. Hipotesis diterima jika setiap variabel independen mempunyai pengaruh positif ke variabel dependen dan mempunyai signifikansi di bawah 0.05. Pengaruh positif kepercayaan terhadap loyalitas ditunjukkan dengan nilai koefesien regresi yang bernilai positif.

\section{Hasil Sampling Data}

Teknik sampling yang digunakan dalam penelitian ini adalah purposive sampling. Purposive sampling adalah salah satu jenis terknik sampling yang menggunakan kriteria-kriteria tertentu dalam pengambilan sampel. Kriteria sampling dalam pengujian ini yakni para nasabah yang mempunyai pinjaman di PD BPR Bank Bantul. Jumlah sampel yang diterima sebanyak 45 responden.

\section{HASIL DAN PEMBAHASAN \\ Deskripsi Data}

Berikut ini adalah data yang menunjukkan rangkuman identitas responden yang disusun berdasar jenis kelamin, usia, dan pekerjaan :

Tabel 1 Deskripsi Usaha Responden

\begin{tabular}{lllllc}
\hline \multicolumn{2}{c}{ Jenis Kelamin } & \multicolumn{2}{c}{ Usia } & \multicolumn{2}{c}{ Pekerjaan } \\
\hline \multicolumn{1}{c}{ JK } & Jumlah & Lama & Jumlah & Karyawan & Jumlah \\
\hline Laki-Laki & 25 & $20-30$ & 10 & PNS/Pegawai & 7 \\
Wanita & 18 & $31-40$ & 13 & Usaha & 36 \\
N/A & 2 & $41-50$ & 14 & N/A & 2 \\
& & $51-60$ & 5 & & \\
& & $>60$ & 0 & & \\
Total & 45 & Notal & 3 & & \\
\hline
\end{tabular}

Berdasarkan data di atas, sebagian besar responden adalah laki-laki. Usia rata-rata responden yakni pada rentang usia 30-50 tahun. Rata-rata pekerjaan responden adalah sebagai usahawan.

\section{Uji Instrumen}

Sebelum dilakukan uji regresi, peneliti menyusun sebuah instrumen dan dilakukan pengujian apakah kuesioner (instrumen) yang disusun sudah memenuhi asumsi validitas dan reliablitas. Terdapat 2 uji instrumen yang digunakan yakni uji validitas dan reliabilitas. Uji validitas digunakan untuk 
menguji apakah instrumen yang dibentuk dapat mengukur apa yang seharusnya diukur. Sedangkan Uji reliabilitas digunakan untuk mengukur sejauh mana hasil pengukuran tetap konsisten. Jumlah sampel yang digunakan dalam uji validitas dan reliabilitas dalam pengujian ini sebanyak 30 responden.

\section{a. Uji Validitas}

Uji validitas dilakukan pada masing-masing variabel. Jumlah item pertanyaan variabel kepercayaan 7 berjumlah pertanyaan dan loyalitas berjumlah 5 pertanyaan. Alat uji yang digunakan dalam uji validitas adalah analisis korelasi (r). Kriteria dikatakan valid dalam pengujian ini adalah :

- Jika skor item masing-masing pertanyaan menunjukkan korelasi positif dengan skor total

- Jika nilai $\mathrm{r}$ hitung item masing-masing pertanyaan lebih besar dari $\mathrm{r}$ tabel

Berikut ini adalah hasil uji validitas pada masing-masing item pertanyaan:

Tabel 2 Uji Validitas

\begin{tabular}{ccccc}
\hline Variabel & Item & R tabel & $\mathrm{R}$ & Valid/Tidak \\
\hline \multirow{5}{*}{ Kepercayan } & 1 & 0.662 & 0.361 & Valid \\
& 2 & 0.787 & 0.361 & Valid \\
& 3 & 0.763 & 0.361 & Valid \\
& 4 & 0.785 & 0.361 & Valid \\
Loyalitas & 5 & 0.770 & 0.361 & Valid \\
& 6 & 0.883 & 0.361 & Valid \\
& 7 & 0.866 & 0.361 & Valid \\
& 2 & 0.751 & 0.361 & Valid \\
& 3 & 0.746 & 0.361 & Valid \\
& 4 & 0.821 & 0.361 & Valid \\
& 5 & 0.441 & 0.361 & Valid \\
& & & & Valid \\
\hline
\end{tabular}

Berdasarkan tabel di atas, semua item pertanyaan yang terdapat pada masing-masing variabel dinyatakan valid. Nilai $\mathrm{r}$ tabel masingmasing item pertanyaan menunjukkan korelasi posititif dan nilai korelasi masing-masing item di atas 0.3 dengan skor total dan nilai $\mathrm{r}$ hitung lebih besar di banding tabel. Dengan demikian setiap item pertanyaan dari masing-masing variabel dapat menjelaskan apa (konseptual) yang sdang diukur.

b. Uji Reliabilitas

Alat uji untuk mengukur reabilitas digunakan adalah cronbach alpha. Uji reliabilitas dilakukan setelah dilakukan uji validitas terlebih dahulu. Jika nilai cronbach alpha di atas 0.6 maka dinyatakan reliabel. 
Berikut ini adalah hasil dari uji reliabilitas untuk masing-masing variabel :

Tabel 3 Uji Reliabilitas

\begin{tabular}{lcc}
\hline Variabel & Jumlah & Cronbach's \\
\hline Kepercayan & 7 & 0.899 \\
Loyalitas & 5 & 0.761 \\
\hline
\end{tabular}

Berdasarkan tabel di atas masing-masing variabel mempunyai nilai cronbach alpha lebih dari 0.6 maka dikatakan reliabel.

\section{Hasil Pengujian Hipotesis}

Setelah semua item pertanyaan memenuhi uji validitas dan reliabilitas, peneliti melakukan uji hipotesis menggunakan analisis regresi. Analis regresi digunakan untuk menguji apakah suatu variabel (X) mempunyai pengaruh terhadap variabel lain (Y). Hipotesis diterima jika setiap variabel independen mempunyai pengaruh positif ke variabel dependen dan mempunyai signifikansi di bawah 0.05. Pengaruh positif menunjukkan hubungan searah antara variabel $\mathrm{X}$ dengan $\mathrm{Y}$ yang ditunjukkan dengan nilai koefesien regresi positif. Berikut ini adalah tabel yang menjelaskan hasil uji regresi linear sederhana

Tabel 4 Hasil Analisis Regresi

\begin{tabular}{lrrrr}
\hline & Coefficients & $t$ Stat & Sig & $R$ Square \\
\hline Intercept & 6.969 & 2.463 & 0.018 & 0.332 \\
\hline $\begin{array}{l}\text { Trust } \\
\text { (Kepercayaan) }\end{array}$ & 0.446 & 4.622 & 0.000 & \\
\hline
\end{tabular}

Persamaan Regresi :

$\mathrm{Y}=6.969+0.446 \mathrm{X}_{1}$

Berdasarkan analisis regresi sederhana di atas maka dapat dinyatakan bahwa hipotesis yang menyatakan "Tingkat Kepercayaan Nasabah Berpengaruh Positif Terhadap Loyalitas" diterima karena mempunyai nilai signifikansi di bawah 0.05 dan koefisien regresi menunjukkan nilai positif.

Kemudian jika ditinjau lebih lanjut lagi berikut ini adalah statistika deskriptif yang menunjukkan tingkat kepercayaan dan loyalitas para nasabah debitur PD BPR Bank Bantul :

Tabel 5 Statistika Deskriptif

\begin{tabular}{lcc}
\hline & Trust & Loyality \\
\hline Average & 4.2 & 4.0 \\
Min & 3.3 & 3.2 \\
Max & 5.0 & 5.0 \\
Median & 4.1 & 4.0 \\
\hline
\end{tabular}

Berdasarkan tabel di atas di rata-rata tingkat kepercayaan para nasabah debitur terhadap PD BPR Bank Bantul pada skala 4,2. Sedangkan 
loyalitas pada skala 4,0. Hal tersebut menunjukkan bahwa para nasabah mempunyai tingkat kepercayaan dan loyaitas yang tinggi pada PD BPR Bank Bantul .

\section{Pembahasan}

Hasil penelitian di atas menunjukkan bahwa kepercayaan pada bank berpengaruh positif dan signifikan terhadap loyalitas atau kesetian nasabah. PD BPR Bank Bantul adalah bank BPR milik permerintah daerah yang beroperasi melayani penghimpunan dana sekaligus penyaluran kredit di sektor UMKM. PD BPR, bank bantul memiliki reputasi yang lebih dibanding bank BPR lain. Adanya reputasi yang baik maka meninimbulkan kesetian (loyalitas). Semakin percaya kepada bank maka semakin loyal nasabah pada bank tersebut. Loyal ditunjukkan dengan a) komitmen tetap mengajukan kredit di BPR Bantul b) tidak terpengaruh oleh iklan atau daya tarik dari lembaga keuangan lain c) sikap merekomendasikan BPR Bantul d) menceritakan hal-hal positif terkait BPR Bantul dan e) menerima tingkat bunga pinjaman yang diberikan oleh BPR Bantul.

Nilai R Square sebesar 0,332 menunjukkan bahwa sekitar 33,2\% loyalitas nasabah bank BPR ditentukan atau dijelaskan oleh kepercayaan sedangkan sisanya sekitar $64,8 \%$ ditentukan oleh faktor lain. Hasil penelitian tersebut sesuai dengan penelitian yang dilakukan terdaulu pada bank BPR dimana kepercayaan beprpengaruh pada loyalitas nasabah.

\section{PENUTUP}

\section{Kesimpulan}

Kesimpulan dari penelitian ini yakni berdasarkan uji regresi liner sederhana, kepercayaan (trust) berpengaruh positif terhadap loyalitas (loyality) dengan tingkat signifikansi di bawah 0,05. Nilai koefisien positif menunjukkan bahwa semakin tinggi kepercayaan nasabah maka semakin tinggi tingkat loyalitas para nasabah.

\section{Saran}

Saran untuk penelitian selanjutnya antara lain

1. Perlu dilibatkan faktor independen lain selain kepercayaan

2. Perlu dikaji lebih jauh tingkat kepercayaan dan loyalitas nasabah

\section{REFERENSI}

Anwar, A.I. (2007). Perilaku Dan Preferensi Masyarakat Sulawesi Selatan Terhadap Bank Perkreditan Rakyat (BPR)

Arfai, A., Valashejerdi, N. F., \& Najafi, Y. (2013). The impact of customer satisfaction and bank image on loyalty: a case study (Sanandaj private banks) using structural equations method. International Research Journal of Applied and Basic Sciences, 4(4), 768-775.

Bank Indonesia. (2016). Perkembangan BAKI Debet Kredit Usaha Mikro, Usaha

Kecil, Dan Usaha Menengah (UMKM) Perbankan1 Outstanding Of Micro, Small, And Medium Enterprises (Msmes) Credits1. 
Bank Indonesia. (2016). Laporan Perkembangan Kredit UMKM Triwulan III 2015.

Departemen Pengembangan UMKM.

Otoritas Jasa Keuangan. (2016). Permasalahan dan Tantangan BPR/BPRS, Rakernas dan Seminar Nasional Perhimpunan Bank Perkreditan Rakyat Indonesia Pontianak, 26 Oktober 2016.

Gudlaugsson, T., \& Eysteinsson, F. (2013). What is the Effect of a Change in Customers' Trust, Following a Banking Collapse, on Their Loyalty towards Their Own Bank? International Journal of Business and Social Science, 4(10), 49-56.

Hazra, S. G., \& Srivastava, K. B. L. (2009). Impact of Service Quality on Customer Loyalty, Commitment and Trust in the Indian Banking Sector. The IUP Journal of Marketing Management, VIII(November).

Ishak, I.M., \& Dama, H. (2014). Survey Persepsi Masyarakat Terhadap Pelayanan Perbankan Di Prov. Gorontalo.

Lailiyah, F.R. (2015). Persepsi Nasabah Terhadap Pelayanan PD BPR Bank Sleman

Setiawan, M. B., \& Ukudi. (2007). Pengaruh Kualitas Layanan, Kepercayaan Dan Komitmen Terhadap Loyalitas Nasabah (Studi Pada PD. BPR Bank Pasar Kendal). Jurnal Bisnis Dan Ekonomi (JBE), 14(2), 215-227.

Silaen, A. B. P. (2004). Faktor-Faktor Yang Mempengaruhi Debitur Terhadap Keinginan Meminjam Pada PT. BPR Sumber Hiobaja Di Baki Sukoharjo. Probank, 10(2), Agustus.

Sirdeshmukh, D., Singh, J., \& Sabol, B. (2002). Consumer Trust, Value, and Loyalty in Relational Exchanges. Journal of Marketing, January, V(1), 15-37. http://doi.org/https://doi.org/10.1509/jmkg.66.1.15.18449

Sumantika. A., Ardiyanto.F. (2017). Draft "Bank BPR, Tinjauan Analisis Dampak Suku Bunga dan Kinerja".

Wijayana, D. P. (2016). Brand Positioning dan Trust terhadap Loyalitas Nasabah (Studi Pada Nasabah BPR Jatim Cabang Batu). EkonomikaBisnis, $7(2), 115-124$.

Wyman, O. (2015). The Future of Customer Loyalty Building a NextGeneration Reward Program. 